REVISTA DE DERECHO UNED, NÚM. 12, 2013

\title{
EL MODELO SOCIAL DE LA DISCAPACIDAD: UNA CUESTIÓN DE DERECHOS HUMANOS
}

\author{
«THE SOCIAL MODEL OF DISABILITY: A MATTER OF HUMAN \\ RIGHTS»
}

\section{Jorge A. Victoria MaLdonado ${ }^{1}$}

Resumen: El modelo social de la discapacidad se presenta como un nuevo paradigma del tratamiento actual de la discapacidad, que ha tenido un desarrollo teórico y también normativo. Es un modelo que considera que las causas que originan la discapacidad no son religiosas, ni científicas, sino que son, en gran medida, sociales. Desde esta nueva perspectiva, se pone énfasis en que las personas con discapacidad pueden contribuir a la sociedad en iguales circunstancias que el resto de las demás personas, pero siempre desde la valorización a la inclusión y el respeto a lo diverso. Este modelo se encuentra íntimamente relacionado con los valores esenciales que fundamentan los Derechos Humanos, como la dignidad humana, la libertad personal y la igualdad, que propician la disminución de barreras y que dan lugar a la inclusión social, que pone como base los principios como: autonomía personal, no discriminación, accesibilidad universal, normalización del entorno, dialogo civil, entro otros. Se parte de la premisa de que la discapacidad es una construcción social, no es la deficiencia que impide a las personas con discapacidad acceder o no a un determinado ámbito social, sino los obstáculos y barreras que crea la misma sociedad, que limitan e impiden que las personas con discapacidad se incluyan, decidan o diseñen con autonomía su propio plan de vida en igualdad de oportunidades.

1 Licenciado en Derecho. Maestro en Administración Pública por la Universidad Anáhuac Mayab. Candidato a Doctor en Derecho por la Universidad Nacional de Educación a Distancia (UNED España). Actualmente es Presidente de la Comisión de Derechos Humanos del estado de Yucatán. 
Palabras clave: Modelo social de la discapacidad, derechos humanos, accesibilidad universal, discriminación, barreras sociales.

Abstract: The social model of disability is presented as a new paradigm of the recent disability treatment, that has had theoretical and legal current development. It is a model that considers that the origins of disability are not either religious or scientific, but social in a great measure. From this new perspective, it is emphasized that the population with disability can contribute to the society in the same circumstances that the rest of the population, which integrates the society, all this from a valorization of the inclusion perspective and respect of diversity. This model is closely related with certain essential values which underline the Human Rights, such as human dignity, individual freedom and equality; all these conduce to a decrease of barriers and lead to a social inclusion that sets basis to principles as: personal autonomy, nondiscrimination, universal accessibility, environmental normalization, civil dialogue, inter alia. The premise is that disability is part of a social construction, and it is not the deficiency what prevents people with a disability to access or not to a particular social sphere, but the obstacles and barriers created by the society itself what limits and prevents people with disability to be included, to decide or to design autonomously their own life plan with opportunity equality.

Keywords: Disability's social model, human rights, universal accessibility, discrimination, social barriers.

Recepción original: 21/05/2013

Aceptación original: 22/05/2013

Sumario: I. A manera de introducción, II. El modelo social de la discapacidad. III. Referencias bibliográficas.

\section{A MANERA DE INTRODUCCIÓN}

Los Derechos Humanos de la población con discapacidad, en la moderna concepción, deben estar dirigidos a equilibrar el acceso al ejercicio pleno de sus derechos y oportunidades en una sociedad dentro de la cual puedan desarrollar libremente y con dignidad sus propios planes y proyectos de vida. La sociedad mexicana ha estado viviendo graves conflictos que influyen negativamente en las personas con discapacidad, pensemos en la inseguridad, la falta de empleo, etc. De tal forma que la posibilidad de ubicar a estos grupos bajo la visión de los Derechos Humanos, consiste e implica con- 
trolar las trasgresiones por parte de las instituciones públicas, así como actos de particulares y de algunos grupos privados que igualmente los agreden. El principio de universalidad de los Derechos Humanos no encaja de manera uniforme en el contexto actual en el que se desarrollan, experimentan y vive este grupo en situación de vulnerabilidad. La aplicación de las concepciones de los Derechos Humanos que no consideren la especificidad y la realidad social de esta población contradice el principio constitucional que garantiza la igualdad real y el trato preferente para las personas con discapacidad. Principios que vemos claramente consagrados en el artículo 1 . $^{\circ}$ de la Constitución mexicana.

En efecto, las personas con discapacidad se presentan actualmente ya en el ámbito de los Derechos Humanos, como titulares plenos de derechos. Por ello, hay que redefinir los derechos, dotarlos de contenido material, hacerlos vinculantes, visibles y exigibles y regular mecanismos sencillos y expeditos de protección de tutela que garanticen su efectividad. Es decir, debe producirse el tránsito de ciudadanos invisibles, debido a las enormes barreras a las que se enfrentan continuamente, a ciudadanos iguales y participativos, por su integración en la vida de la comunidad. ${ }^{2}$ En las últimas décadas estamos viendo un desarrollo importante, que va en ascenso, en los cambios que se están produciendo en nuestras sociedades occidentales respecto a las personas con discapacidad. Estos cambios, que se notan en todos los ámbitos, han supuesto una transformación en el propio modelo en que se estructura la forma de percibir y tratar a las personas con discapacidad en nuestras sociedades, pasándose de lo que se conoce como modelo rehabilitador al actual modelo social, que significa entender la cuestión de la discapacidad como una cuestión de Derechos Humanos, señalando cómo este modelo supone un progreso frente a los modelos anteriores: el de prescindencia, el de marginación y el rehabilitador. ${ }^{3}$ Precisamente en las últimas décadas la discapacidad ha sido considerada como una construcción sociocultural dentro de un discurso basado en derechos, inspirada por los movimientos sociales de la década de los setenta. Los activistas de la discapacidad enfrentan la tarea de recrear la cultura de la diferencia, celebrando la diferencia. Se plantean debates muy intensos sobre la

2 Vid; MARTÍNEZ, J. L., (ed.), Exclusión Social y discapacidad, Madrid, España, Universidad Pontificia de Comillas, 2005, p. 123.

3 Vid; CAMPOY CERVERA I., Los derechos de las personas con discapacidad. Perspectivas sociales, politicas, jurídicas y filosóficas, Madrid, Carlos III-Dykinson, 2004, p. 10. 
relación entre conceptos de equidad, igualdad, diferencia, similitud y su relación con los debates de la discapacidad ${ }^{4}$.

En efecto, hemos de comprender, que en la actualidad se está pasando de la percepción de las personas con discapacidad, como personas con discapacidad, como personas enfermas, que debían de superar carencias y deficiencias a fin de adaptarse lo mejor posible a la sociedad existente, para lo que se les ofrecía el adecuado tratamiento médico, o en su caso, prestaciones económicas o sociales, que eran entendidas casi como beneficencia; a la percepción de las personas con discapacidad como un colectivo de personas que se encuentran en una especial situación de desventaja social debido a que la sociedad ha construido un entorno ${ }^{5}$ preparado sólo para un determinado estándar de personas, con unas determinadas características, y para solucionar ese estado de cosas lo que se ha de reconocer son los derechos de igualdad y no discriminación también de las personas con discapacidad; y lograr, por consiguiente, que sea la sociedad la que se adapte para dar espacios a toda clase de personas ${ }^{6}$. Un cambio puede verse reflejado, en buena medida, en la evolución jurídica que se ha seguido en Yucatán (México), es la reciente expedición de la Ley para Prevenir y Eliminar la Discriminación del Estado de Yucatán ${ }^{7}$, en la que se reconocen los derechos a la igualdad y no discriminación y la accesibilidad universal de las personas con discapacidad, así como la promulgación del reglamento respectivo, con lo que se abre el camino a la instauración de políticas pública eficaces para este sector poblacional.

Es necesario, entonces, como parte de una sociedad que empieza a reconocerse como una unidad en la diferencia, de manera especial y en el marco del enfoque de los Derechos Humanos, efectuar un estudio detallado que amplíe los horizontes de la dignidad humana y propicie que la calidad de vida se equilibre en beneficio de las personas con discapacidad. Estamos convencidos que los Derechos Humanos, además de ser pensados de manera que respondan a la di-

4 MORENO, ANGARITA, M., «Pistas para el diálogo entre salud pública y discapacidad: hacia una comprensión de la evolución del concepto de discapacidad», Cuadernos del doctorado $n .^{\circ} 8$, Salud pública y discapacidad, Universidad Nacional de Colombia, 2008, p. 76.

5 Podemos definir el entorno como: «el conjunto de elementos naturales y artificiales donde se desarrolla la vida humana». Vid; POLONIO, B., / RUIZ, J., "Accesibilidad integral», en, Rehabilitación clínica integral: funcionamiento y discapacidad, Barcelona España, Ed. Masson, 2003, p. 437.

6 Vid; Vid; CAMPOY CERVERA I., Los derechos de las personas con discapacidad. Perspectivas sociales, políticas, jurídicas y filosóficas, Op. Cit., p. 10.

7 Publicada en el Diario Oficial del Estado el 6 de julio de 2010. 
versidad cultural y la diferencia, deben pensarse también de distinta manera. Para caracterizar esta distinta forma de ejecutar los Derechos Humanos, sugerimos tres líneas de reflexión que se interrelacionan de diferente forma: La primera, se relaciona con la capacidad que tiene un grupo de conocerse a sí mismo sobre la base de elementos fundados en el desarrollo de su propia realidad. En esta línea de análisis se resuelve los cuestionamientos ¿Quiénes somos? ¿Cómo pensamos? La segunda línea se enmarca en una identificación social, según la cual nos reconocemos como miembros, pero también reconocemos al otro, es decir, como sociedad definimos y luchamos por espacios en donde podamos participar y ser tenidos en cuenta. Esta línea resuelve el interrogante; Como grupo diferenciado por discapacidad ¿cómo podemos ser tenidos en cuenta dentro de la mayoría? ${ }^{8}$

Finalmente, la tercera línea de reflexión se refiere a la política pública que articula el conocimiento con la sociedad, en la medida en que el conocernos como sociedad o conocer otras sociedades implica poder exigir derechos y obtenerlos conlleva igualmente a que éstos sean reconocidos. Tal reconocimiento involucra la participación en todos los ámbitos de la sociedad. Esta tercera línea determina concepciones básicas relativas al disfrute de los derechos; preguntas como ¿qué derechos tienen las personas con discapacidad como minoría o grupo vulnerable? En este sentido, nos proponemos insistir en la importancia de valorar la eficacia de los mecanismos jurídicos que garantizan los derechos de las personas con discapacidad en el Estado mexicano. Así como la eficacia de las instituciones de orden nacional y estatal que propenden por el bienestar de este grupo vulnerable. Un análisis profundo de la realidad de la discapacidad en nuestro país, debe incluir temas como: determinar la situación actual de la población con discapacidad en México, analizando aspectos sociales, económicos y culturales; establecer el marco normativo vigente nacional y estatal para determinar cuáles aspectos pueden mejorar, buscando una regulación reflejo de la realidad mexicana; establecer cuáles son los derechos que más se garantizan o se vulneran a las personas con discapacidad y analizar cuál es la legislación vigente en el derecho internacional que protege y garantiza los derechos de las personas con discapacidad, determinando su incorporación a la normativa interna mexicana.

La respuesta a estos cuestionamientos permitirá generar una propuesta que aporte mayores garantías a las personas con discapacidad en los conflictos sociales, recomendaciones y propuestas para

8 Vid; PARRA DUSSAN, C., (Ed.), Derechos Humanos y discapacidad, Bogotá, Colombia, Centro Editorial Universidad del Rosario, 2004, pp. 15-16. 
que el Estado se ajuste a la normatividad nacional e internacional y a los principios constitucionales que rigen esta materia.

\section{EL MODELO SOCIAL DE LA DISCAPACIDAD}

El avance en la comprensión de la discapacidad y su teorización no es un proceso aislado de la realidad que se sitúa sólo en el plano de las ideas. Resulta evidente que está interrelacionado e impulsado por los acontecimientos socio-políticos, culturales y económicos que suceden en cada época histórica. Así, desde las décadas de los años sesenta y setenta del siglo XX, especialmente en el contexto de Estados Unidos, Gran Bretaña, países escandinavos, y más recientemente España, aparecen diversos movimientos sociales por parte de colectivos «desfavorecidos», como personas de raza negra y otras minorías étnicas, mujeres y personas con discapacidad, que denuncian su situación de marginación y piden el reconocimiento de sus derechos civiles como ciudadanos y ciudadanas en situación de igualdad social. En el caso de las personas con discapacidad surge en Estados Unidos el denominado Independent Living Movement (Movimiento de Vida Independiente), y otros grupos de similares características en otros países. Estos movimientos nacen y son promovidos por los propios discapacitados y discapacitadas y sus familias, que rechazan la vida en instituciones apartadas y el ser sometidas a programas de rehabilitación, sin tener ningún control sobre sus vidas. Estas personas manifiestan que se sienten «oprimidas» y reclaman sus derechos pidiendo tomar por sí mismas las riendas de sus vidas 9 .

Es así que desde esta perspectiva de las políticas emancipadoras, cobran importancia las concepciones sobre persona y sobre sujeto, y los Derechos Humanos se ubican como los argumentos necesarios y oportunos para sacar de los límites al discapacitado y ubicarlo dentro de la sociedad como un actor social. De este modo el problema de la discapacidad no está en el individuo sino en la sociedad que lo rodea, en el contexto que lo acoge o lo rechaza ${ }^{10}$. Una de las tentativas iniciales de aproximar la discapacidad a la cultura de los Derechos Humanos fue hecha en Inglaterra en la década de 1970, a raíz de que un grupo de activistas con discapacidad que denuncian

9 Vid; BARNES, C., «Las teorías de la discapacidad y los orígenes de la opresión de las personas discapacitadas en la sociedad occidental», en, BARTON, L. (Comp.). Discapacidad y Sociedad, Madrid Morata, 1998, pp. 59-76.

10 Vid; MUÑ́́Z BORJA, P., Construcción de sentidos del mundo de la discapacidad y la persona con discapacidad. Estudios de casos, Cali, Colombia, Universidad del Valle, 2006, p. 69. 
su situación de marginación y pedían el reconocimiento de sus derechos civiles como ciudadanos y ciudadanas en situación de igualdad social. Con ello se propuso los Principios Fundamentales de la Discapacidad. Posteriormente, Mike Oliver presentó este conjunto de líneas bajo la denominación del modelo social de la discapacidad ${ }^{11}$. En el mismo, se establecía, por primera vez, una diferenciación entre la deficiencia y la discapacidad, al tiempo que se explicaba que la discapacidad tenía que ser abordada holísticamente, es decir, como un todo, ya que en ella confluían una serie de dimensiones. Así el modelo social ha enfatizado en las barreras económicas, medioambientales y culturales en el contexto. Entre las barreras mencionadas, se señalan de una forma pormenorizada la inaccesibilidad a la educación, a los sistemas de comunicación e información, a los entornos laborales, al transporte, a las viviendas y los edificios públicos, o a los de servicio de apoyo social y sanitarios no discriminatorios. Se refiere a la devaluación de las personas etiquetadas por la imagen y su representación negativa en los medios de comunicación. Se señala que las personas con deficiencias son discapacitadas debido al rechazo de la sociedad a acomodar las necesidades individuales y colectivas dentro de la actividad general de la vida, económica y cultural ${ }^{12}$.

Este modelo social de la discapacidad considera que las causas que originan la discapacidad no son ni religiosas, científicas, sino que son, en gran medida sociales ${ }^{13}$. En efecto este nuevo paradigma social sobre la discapacidad, que se enmarca en los principios generales declarados por los Derechos Humanos, se origina en la segunda mitad del siglo pasado. Este movimiento multidimensional nace dentro de la disciplina de las ciencias sociales, el análisis de las políticas sociales y la lucha por los derechos civiles; específicamente aquellos relacionados con los derechos de las personas con discapacidad ${ }^{14}$. En

11 Vid; OLIVER, M., ¿Una sociología de la discapacidad o una sociología discapacitada? En L. BARTON (Comp.). Discapacidad y sociedad, Madrid, Morata, 1998, pp. 34-58. Del mismo autor vid; The Politics of Disablement. Basingstoke: McMillan, 1990. Understanding Disability. Basingstoke: McMillan, 1996.

12 Vid; BARNES, C., (1998). "Las teorías de la discapacidad y los orígenes de la opresión de las personas discapacitadas en la sociedad occidental». En L. Barton (Comp.). Discapacidad y Sociedad, Madrid: Morata, p. 64. También vid; DÍAZ BALADO, Alicia: "La inserción laboral de las personas con discapacidades en la Provincia de A Coruña desde una perspectiva de género». Santiago de Compostela: Universidade. Servizo de Publicacións e Intercambio Científico, 2009, p. 79.

13 La utilización del término social en este caso pretende subrayar que las causas que originan la discapacidad no son individuales - de la persona afectada-, sino sociales-por la manera en que se encuentra diseñada la sociedad-.

14 Vid; FRASER, V., "Opening Remarks», en, Challenging Orthodoxies: New perspective in Disability. Proceedings of Research in disability and public policy summer Institute, Toronto, Canadá, Roeher Institute. Vid; FLORES BRISEÑO, G. A., «El 
sus diferentes estructuras y contenidos, esta nueva propuesta encaminada tanto hacia la investigación social, la actualización de las políticas públicas, como a la consolidación de los Derechos Humanos de las personas con discapacidad, se conoce como el modelo social de la discapacidad ${ }^{15}$. En este nuevo paradigma, al considerar que las causas que están en el origen de la discapacidad son sociales, pierde parte de sentido la intervención puramente médica o clínica. Las soluciones no deben tener cariz individual respecto de cada persona concreta afectada, sino que más bien deben dirigirse a la sociedad ${ }^{16}$.

A diferencia del modelo médico, el cual pone énfasis en el tratamiento de la discapacidad, orientado a conseguir la cura, o una mejor adaptación de la persona, o un cambio en su conducta, situando el problema de la discapacidad dentro del individuo, considerándose que las causas de dicho problema son el resultado exclusivo de las limitaciones funcionales o pérdidas psicológicas, que son asumidas como originadas por la deficiencia; el modelo social pone énfasis en la rehabilitación de una sociedad, que ha de ser concebida y diseñada para hacer frente a las necesidades de todas las personas, gestionando las diferencias e integrando la diversidad ${ }^{17}$. En efecto, este modelo de Derechos Humanos se centra en la dignidad del ser humano y después, pero sólo en caso necesario, en las características médicas de la persona. Sitúa al individuo en el centro de todas las decisiones que le afectan y, lo que es aún más importante, sitúa el problema principal fuera de la persona, en la sociedad. En este modelo, el problema de la discapacidad se deriva de la falta de sensibilidad del Estado y de la sociedad hacia la diferencia que representa esa discapacidad. De ello se deduce que el Estado tiene la responsabilidad de hacer frente a los obstáculos creados socialmente a fin de garantizar el pleno respeto de la dignidad y la igualdad de derechos de todas las personas ${ }^{18}$.

modelo médico y el modelo social de la discapacidad: un análisis comparativo", en, RIBEIRO FERREIRA, M., / LÓPEZ ESTRADA, R, E., (eds.), Politicas Sociales Sectoriales: tendencias actuales, Tomo II, México, Universidad Autónoma de Nuevo León, 1999, pp. 239-250.

15 Vid; BOORSE, C., «Health as a theoretical concept», Philosophy of Science, 1977, pp. 44, 542-549. También vid; FLORES BRISEÑO, G. A., «El modelo médico y el modelo social de la discapacidad: un análisis comparativo», Op. Cit., pp. 239-240.

16 Vid; PÉREZ BUENO, L. C., Discapacidad, Derecho y Politicas Públicas, Madrid, Ed. Cinca, 2010, p. 84

17 Vid; PÉREZ BUENO, L. C., Discapacidad, Derecho y Políticas Públicas, Op. Cit p. p. 84

18 Vid; QUINN, G., / DEGENER T., (Eds.), Derechos Humanos y Discapacidad: Uso actual y posibilidades futuras de los instrumentos de Derechos Humanos de las 
El modelo social caracteriza a la persona con discapacidad a partir de: a) El cuerpo, más que identificar qué tan completo está anatómicamente y qué tan cerca funcione de acuerdo con la norma, las personas que optan por poner en práctica este modelo se centra en descubrir las habilidades y las capacidades que este individuo ha desarrollado con el cuerpo que posee, para luego, a través de procedimientos sistemáticos, potenciarlas; b) El entorno inmediato (la familia), se tiene en cuenta el proceso por el cual pasan sus miembros al recibir la noticia de que uno de ellos ha sufrido una lesión o dificultad que desembocará en una discapacidad. Según cómo evolucione ese proceso, los miembros de su familia construirán un concepto de su familiar, y justamente este concepto facilitará o entorpecerá el desarrollo de habilidades y capacidades que intervendrán de manera directa en su mayor o menor integración, primero en la familia y luego en los otros entornos. Aquí cobra importancia el proceso socializador, pues se parte del supuesto de que es éste el que puede facilitar o entorpecer la integración de las personas con discapacidad, dependiendo de las ideas, sentimientos e imágenes que cada miembro de la familia tenga sobre la discapacidad y de las prácticas sociales que desarrollen para lograr el equilibrio, y c) El medio, como portador de oportunidades en términos de la equidad y de la eliminación de barreras, o como portador de riesgos, para realizar acciones de prevención de la discapacidad ${ }^{19}$.

Según los defensores de este modelo, no son las limitaciones individuales las raíces del problema, sino las limitaciones de la propia sociedad para prestar los servicios apropiados y para asegurar adecuadamente que las necesidades de las personas con discapacidad sean tenidas en cuenta dentro de la organización social. ${ }^{20}$ Precisamente, desde este modelo se insiste en que las personas con discapacidad pueden aportar a la sociedad en igual medida que el resto de personas, -sin discapacidad-, pero siempre desde la valoración y el respeto de la diferencia. Este modelo se encuentra íntimamente relacionado con la asunción de ciertos valores intrínsecos a los Derechos Humanos y aspira a potenciar el respeto por la dignidad humana, la igualdad y la libertad personal, propiciando la inclusión social, y sentándose sobre la base de determinados principios: autonomía

Naciones Unidas en el contexto de la discapacidad, .Nueva York y Ginebra, Doc. HR/ PUB/02/1, Naciones Unidas, 2002, pp. 11 y ss.

19 Vid; MUÑ́́Z BORJA, P., Construcción de sentidos del mundo de la discapacidad y la persona con discapacidad. Estudios de casos, Op. Cit., pp. 69-70.

20 Vid; PALACIOS, A., El modelo social de discapacidad: orígenes, caracterización y plasmación en la Convención Internacional sobre los Derechos de las Personas con Discapacidad, Op. Cit., p. 104. 
personal, no discriminación, accesibilidad universal, normalización del entorno, dialogo civil, entre otros. Parte de la premisa de que la discapacidad es una construcción y un modo de opresión social y resultado de una sociedad que no considera ni tiene presente a las personas con discapacidad. De igual manera, apunta a la autonomía personal de la persona con discapacidad para decidir respecto de su propio proyecto de vida. Para ello, se centra en la eliminación de cualquier tipo de barrera, y los fines de brindar una real igualdad de oportunidades $^{21}$.

Abriendo un pequeño paréntesis, es preciso mencionar que, en igualdad de oportunidades o igualdad en el punto de partida, el reparto definitivo de los bienes sociales depende de los méritos y el esfuerzo de cada persona. De tal manera, que las acciones del Estado se dirigen básicamente al ámbito educativo, el equilibrio de las cargas familiares y la concientización social ${ }^{22}$. El profesor John Rawls precisa la idea de igualdad de oportunidades en el sentido de que «los que poseen el mismo nivel de talento y habilidad y la misma disposición a hacer uso de esos dones, deberían tener las mismas perspectivas de éxito independientemente de su clase social de origen. [...] En todas las partes de la sociedad debe haber aproximadamente las mismas perspectivas de cultura y logro para los que están similarmente motivados y dotados ${ }^{23}$.

En este sentido, la igualdad de oportunidades se interpreta actualmente no en el sentido formal que tuvo en un principio-al modo como lo entendía el liberalismo clásico-, donde se pretendía que tan sólo eliminando barreras y estableciendo una igualdad de derechos se obtendrían posiciones laborales o sociales a través del mérito personal, es decir, se trataba de un modelo de libertades formales. Por el contrario, la igualdad de oportunidades en sus alcances actuales implica ser efectiva, no únicamente formal, y para que sea efectiva necesita no sólo el igual acceso a las posiciones, sino también igualdad en los resultados ${ }^{24}$. La igualdad en los resultados o la igualdad en el punto de llegada se determina en los términos de lo justo, lo bueno, lo equitativo; esto es, la participación de todos los grupos en

21 Vid; PALACIOS, A., El modelo social de discapacidad: orígenes, caracterización y plasmación en la Convención Internacional sobre los Derechos de las Personas con Discapacidad, Op. Cit., pp. 26-27.

22 Vid; PÉREZ PORTILLA, Karla, Principio de igualdad: alcances y perspectivas, México, UNAM-IIJ, 2005, pp. 155-157

23 RAWLS John, La justicia como equidad. Una reformulación, España, Ed. Paidós, 2001, p. 74.

24 Vid; FERNÁNDEZ Encarnación, Igualdad y derechos humanos, España, Ed. Tecnos, 2003, pp. 121 y ss. 
cada uno de los ámbitos de la sociedad: trabajo, educación, capacitación, y obtención de bienes y servicios. Y en este punto, la falta de accesibilidad de las personas con discapacidad a estos ámbitos antes referidos, como el educativo, el laboral, los espacios públicos, etc, resulta fundamental para la construcción de un modelo social de la discapacidad.

Este modelo social de la discapacidad, pretende evaluar la interacción entre las personas con discapacidad, la interacción entre ellas, el medio ambiente dentro del cual se desempeñan y la sociedad. Las investigaciones que se han realizado han permitido establecer que, aún cuando una persona con discapacidad interactúa socialmente en forma diferente a otras personas, los problemas que confrontan no son originados debido a su discapacidad, sino principalmente a las actitudes que la sociedad manifiesta hacia la discapacidad ${ }^{25}$. Por ello, es la interacción de las diferentes limitaciones funcionales con los factores ambientales, la que en realidad determina que una persona exteriorice una discapacidad. En este sentido, la discapacidad está determinada por la diferencia que existe entre las habilidades de una persona, las demandas sociales y las limitaciones impuestas por el medio ambiente. Manifiesta cierta discapacidad debido a que es confrontada con un ambiente socio-cultural que le es discriminante y hostil. Se puede decir por ejemplo, que la discapacidad física o intelectual, no es un atributo de la persona, sino más bien el resultado de una serie de elementos condicionantes, o actividades y relaciones interpersonales restringidas por el contexto social, económico y político de un país ${ }^{26}$.

Esta forma de pensar ha llevado a que las Organizaciones Sociales que representan los intereses e ideales de las personas con discapacidad, argumenten que la discapacidad ha sido considerada como elemento político de un sector social marginado que reclama la falta de igualdad e inclusión real en el sector laboral, vivienda y transporte. La falta de igualdad de oportunidades no es consecuencia real de la condición médica en sí misma, sino en gran medida de las actitudes de la marginación social y la discriminación, con la

25 Vid; QUINN, P., «Social Work and Disability Management Policy: Yesterday, today, and tomorrow», Social Work in Health Care, 1995, pp. 20, 67-82. También vid; FLORES BRISEÑO, G. A., «El modelo médico y el modelo social de la discapacidad: un análisis comparativo», Op. Cit., pp. 242-243.

26 Vid; BICKENBACH, J. E., «Minority rights or Universal participation: The politics of disablement», en, JONES, M., /BASSER, M., (Eds.), Disability, Diversability and Legal Change, Martinus Nijhoff/Kluwer Dordrecht, 1999, pp. 101-116. Citado por, FLORES BRISEÑO, G. A., «El modelo médico y el modelo social de la discapacidad: un análisis comparativo», Op. Cit., pp. 242-243. 
creación de estereotipos que implícitamente niegan o rechazan las habilidades y necesidades de las personas con discapacidad ${ }^{27}$. Puede decirse entonces, que el modelo social de la discapacidad, visualiza y ubica el problema de la discapacidad dentro de la misma sociedad ${ }^{28}$. El esfuerzo por lograr una plena integración de las personas con discapacidad debe orientarse hacia la eliminación, o al menos a la continua disminución de las barreras ambientales, físicas e ideológicas que limitan la participación e integración de las personas con discapacidad dentro de la sociedad ${ }^{29}$.

La inclusión social y económica, junto con la completa participación de las personas con discapacidad, depende de la estructuración y ampliación de un nuevo marco fundamentado en el significado real de la discapacidad dentro del contexto social moderno. Este nuevo marco conceptual será aquel que genere acciones sociales incluyentes que permitan a las personas con discapacidad vivir satisfactoriamente, ser útiles y económicamente independientes. Dicho marco, deberá satisfacer las normas nacionales e internacionales del bienestar, los Derechos Humanos, la democracia y los principios de ciudadanía. La aparición de este nuevo modelo, permitirá una visión holística encaminada hacia los sistemas y estructuras sociales, más que a resaltar las patologías, deficiencias y minusvalías de las personas. Actualmente las políticas sociales se han orientado hacia el ejercicio de aquellas acciones que faciliten la estructuración de las sociedades más incluyentes, más participativas y respetuosas de los Derechos Humanos ${ }^{30}$. Como bien sostiene la profesora Ana Rosa Martín Minguijón, es necesario que los poderes públicos promuevan estas políticas que garanticen el ejercicio efectivo en igualdad de condiciones, siendo que las mismas, de carácter positivas o negativas, estén dirigidas a eliminar discriminaciones que supongan una violación auténtica de los derecho derechos humanos de las personas con discapacidad, y se traduzcan en la existencia de institucio-

27 Vid; GARTNER, A., /JOE, T., Images of the disabled: Disabling images, New York, Praeger, 1987. Citado por FLORES BRISEÑO, G. A., "El modelo médico y el modelo social de la discapacidad: un análisis comparativo», Op. Cit., pp. 242-243

28 Vid; QUINN, P., Understanding Disability A Lifespan Approach, SAGE Publications, 1998. También vid; FLORES BRISEÑO, G. A., «El modelo médico y el modelo social de la discapacidad: un análisis comparativo», Op. Cit., pp. 242-243

29 Vid; FRENCH, S., "Disability impairment or Something in between?», en, FINKELSTEIN, V., FRENCH, S., OLIVER, M., (Eds.), Disabling barriers: Enabling environments, London, SAGE, 1993, pp. 17-25. Citado por, FLORES BRISEÑO, G. A., «El modelo médico y el modelo social de la discapacidad: un análisis comparativo», Op. Cit., p. 243.

30 Vid; FLORES BRISEÑO, G. A., «El modelo médico y el modelo social de la discapacidad: un análisis comparativo», Op. Cit., p. 249. 
nes y en medidas que tengan como objetivo la autonomía personal y la plena integración social ${ }^{31}$. Sin duda alguna, como bien lo señala la profesora Ana Rosa Martín, la no accesibilidad constituye una forma sutil pero muy eficaz de discriminación, por lo tanto, el objetivo de la norma jurídica y de las políticas públicas en esta materia, será la de garantizar la igualdad de oportunidades de las personas con discapacidad como resultado de sumar la ausencia de marginación y discriminación con las medidas de acción positiva inspiradas en los principios de vida independiente, normalización, accesibilidad universal, diseño para todos, diálogo civil y transversalidad de las políticas de Estado en materia de discapacidad ${ }^{32}$.

La vida de una persona con discapacidad tiene el mismo sentido que la vida de una persona sin discapacidad. En esta línea, las personas con discapacidad remarcan que ellas tienen mucho que aportar a la sociedad, pero para ello deben ser aceptadas tal y cual son, ya que su contribución se encuentra supeditada y asimismo muy relacionada con la inclusión y la aceptación de la diferencia. El objetivo que se encuentra reflejado en este paradigma es rescatar las capacidades en vez de acentuar las discapacidades ${ }^{33}$. En definitiva, puede forjarse un poderoso vínculo entre el modelo social de la discapacidad y la perspectiva de la discapacidad basada en los Derechos Humanos ${ }^{34}$. La sociedad no ha tenido en cuenta o ha ex-

31 Vid; MARTÍN MINGUIJÓN, Ana Rosa, «El menor con discapacidad. Precariedad en la regulación y en políticas específicas», en, AA.VV., Los menores con discapacidad en España, Madrid, Ediciones CINCA, CERMI, 2008, p. 410.

32 Vid; MARTÍN MINGUIJÓN, Ana Rosa, «El menor con discapacidad. Precariedad en la regulación y en políticas específicas», Op. Cit., pp. 410-411.

33 Vid; PALACIOS, A., El modelo social de discapacidad: orígenes, caracterización y plasmación en la Convención Internacional sobre los Derechos de las Personas con Discapacidad, Op. Cit., pp. 104-105.

34 Una variable de este modelo, está constituida por lo que podríamos denominar como modelo de la diversidad. Se trata de un modelo basado en los postulados de los movimientos de vida independiente y que, demandan la consideración de la persona con discapacidad (o con diversidad funcional, término que se utiliza por este movimiento y que ya está cobrando éxito), como un ser valioso en sí mismo por su diversidad. El modelo de la diversidad compartiría la visión de la situación de dependencia del modelo social, si bien podría añadirse que la situación que la provoca no tiene porqué ser considerada siempre como un mal o una limitación (ya sea individual o social). La persona con discapacidad o el mayor (al igual que el menor) es, sencillamente, una persona diversa a otra, con lo que su presencia en las sociedades (obviamente en igual satisfacción de derecho que el resto) es un verdadero factor de enriquecimiento. En términos de derechos, el modelo de la diversidad demanda el reconocimiento de derechos específicos de estos grupos, no tanto desde una argumentación de tipo individualista, sino más bien de tipo particularista. Vid; DE ASÍS ROIG, R., / PALACIOS A., Derechos humanos y situaciones de dependencia, Madrid, Universidad Carlos III-Dykinson, 2007, p. 27. 
cluido la diferencia implícita en la discapacidad a la hora de regular las condiciones de acceso y de participación en el contexto social. El objeto último desde la perspectiva del modelo de Derechos Humanos es construir sociedades que sean auténticamente integradoras, sociedades que valoren la diferencia y respeten la dignidad, la igualdad de todos los seres humanos con independencia de sus diferencias y discapacidades ${ }^{35}$. Ello porque se considera que la discapacidad no es simplemente un atributo de la persona, sin un complejo conjunto de condiciones, muchas de las cuales son creadas por el contexto social. En consecuencia, el manejo del tema se requiere la realización de todas las modificaciones y adaptaciones necesarias, a los fines de alcanzar la participación plena de las personas con discapacidad en la totalidad de las áreas de la vida en comunidad. Por lo tanto, se requiere de la introducción de una serie de cambios sociales, muchos de ellos -tal vez todos- relacionados con los Derechos Humanos; lo importante será centrar nuestra reflexión en aquellas discapacidades que ubican a un sujeto en una situación de desventaja en el ámbito de la participación en la vida social; por lo tanto, se requiere de la búsqueda de soluciones a partir del respeto a los principios y valores esenciales que fundamentan los Derechos Humanos ${ }^{36}$.

En definitiva, decir que la discapacidad es un problema social implica además: a) que la problemática debe ser entendida en un contexto social, cultural, histórico y geográfico; b) que la deficiencia o daño de la persona afectada implica sólo una parte de la situación de discapacidad; c) que la resolución del problema implica tanto una adecuada rehabilitación como contar con una sociedad accesible; d) que una sociedad es accesible cuando depone barreras de todo tipo; e) que las barreras culturales constituyen la base donde se formulan las tangibles y las de tipo físico. Una sociedad es accesible cuando practica la tolerancia y el respeto hacia la diferencia, valorándola

35 Vid; QUINN, G., / DEGENER T., (Eds.), Derechos Humanos y Discapacidad: Uso actual y posibilidades futuras de los instrumentos de Derechos Humanos de las Naciones Unidas en el contexto de la discapacidad, Op. Cit., p. 13.

36 Vid; DE ASIS ROIG, R., /AIELLO, A. L., / BARIFFI, F., / CAMPOY CERVERA, I., / PALACIOS, A., Sobre la accesibilidad en el Derecho, Madrid, Universidad Carlos III-Dykinson, 2007, p. 24. De los mismos autores también vid; «La accesibilidad universal en el marco constitucional español», Derechos y libertades, n. ${ }^{\circ} 16$, enero 2007, p. 60. También vid; DE ASIS ROIG, R., «La incursión de la discapacidad en la teoría de los derechos», en, CAMPOY CERVERA, I., (Ed.), Los derechos de las personas con discapacidad: perspectivas sociales, políticas, jurídicas y filosóficas, Madrid, Ed. Dykinson, 2004, pp. 66 y ss. También vid; DE ASÍS ROIG, F., «Derechos Humanos y discapacidad. Algunas reflexiones derivadas del análisis de la discapacidad desde la teoría de los derechos humanos», en, JIMÉNEZ, E., (Ed.), Igualdad, No discriminación y Discapacidad, Buenos Aires Argentina, Ed. Ediar-Dykinson, 2003, pp. 17-48. 
como algo positivo, única forma de construir una democracia verdadera. En conclusión, detrás de la cuestión de la discapacidad se encuentra el análisis más profundo aún, sobre el tipo de democracia que se pretende construir. Por ello, para el profesor Santiago Martín, «la actividad del jurista y del legislador no debe necesariamente focalizarse en las personas con discapacidad, y a veces ni siquiera en la discapacidad misma, sino en la sociedad y sus comportamientos para con ellos. Es la sociedad quien sufre discapacidades para valorar lo diferente, para entender las necesidades de quienes sufren impedimentos físicos, y para incluir a estos en la vida comunitaria» ${ }^{37}$.

Ante este desafío, el papel que debe cumplir el Derecho, y más específicamente el Derecho Internacional de los Derechos Humanos, ha de ser activo, convirtiéndose en un factor de cambio que logre generar actitudes tolerantes e inclusivas.

\section{REFERENCIAS BIBLIOGRÁFICAS}

BARNES, C., «Las teorías de la discapacidad y los orígenes de la opresión de las personas discapacitadas en la sociedad occidental», en, BARTON, L. (Comp.). Discapacidad y Sociedad, Madrid Morata, 1998.

BICKENBACH, J. E., «Minority rights or Universal participation: The politics of disablement», en, JONES, M., /BASSER, M., (Eds.), Disability, Diversability and Legal Change, Martinus Nijhoff/Kluwer Dordrecht, 1999.

BOORSE, C., «Health as a theoretical concept», Philosophy of Science, 1977.

CAMPOY CERVERA I.,, Los derechos de las personas con discapacidad. Perspectivas sociales, politicas, jurídicas y filosóficas, Madrid, Carlos III-Dykinson, 2004.

DE ASÍS ROIG, R., / PALACIOS A., Derechos humanos y situaciones de dependencia, Madrid, Universidad Carlos III-Dykinson, 2007.

DE ASIS ROIG, R., / AIELLO, A. L., / BARIFFI, F., / CAMPOY CERVERA, I., / PALACIOS, A., Sobre la accesibilidad en el Derecho, Madrid, Universidad Carlos III-Dykinson, 2007.

37 MARTÍN J. SANTIAGO, «La discapacidad como un problema social de derechos humanos», en, CAMPOY CERVERA, Ignacio, PALACIOS Agustina, (Eds.), Igualdad, no discriminación y discapacidad. Una visión integradora de las realidades española y argentina, Madrid, Universidad Carlos III-Dykinson, 2007, p. 106. 
DE ASIS ROIG, R., «La incursión de la discapacidad en la teoría de los derechos», en, CAMPOY CERVERA, I., (Ed.), Los derechos de las personas con discapacidad: perspectivas sociales, politicas, jurídicas y filosóficas, Madrid, Ed. Dykinson, 2004.

- «Derechos Humanos y discapacidad. Algunas reflexiones derivadas del análisis de la discapacidad desde la teoría de los derechos humanos», en, JIMÉNEZ, E., (Ed.), Igualdad, No discriminación y Discapacidad, Buenos Aires Argentina, Ed. EdiarDykinson, 2003.

DÍAZ BALADO, A., «La inserción laboral de las personas con discapacidades en la Provincia de A Coruña desde una perspectiva de género», Santiago de Compostela: Universidade, Servizo de Publicacións e Intercambio Científico, 2009.

FERNÁNDEZ, Encarnación, Igualdad y derechos humanos, España, Ed. Tecnos, 2003.

FLORES BRISEÑO, G. A., «El modelo médico y el modelo social de la discapacidad: un análisis comparativo», en, RIBEIRO FERREIRA, M., / LÓPEZ ESTRADA, R, E., (eds.), Politicas Sociales Sectoriales: tendencias actuales, Tomo II, México, Universidad Autónoma de Nuevo León, 1999.

FRASER, V., «Opening Remarks», en, Challenging Orthodoxies: New perspective in Disability. Proceedings of Research in disability and public policy summer Institute, Toronto, Canadá, Roeher Institute.

FRENCH, S., «Disability impairment or Something in between?», en, FINKELSTEIN, V., FRENCH, S., OLIVER, M., (Eds.), Disabling barriers: Enabling environments, London, SAGE, 1993.

GARTNER, A., /JOE, T., Images of the disabled: Disabling images, New York, Praeger, 1987.

MARTÍN MINGUIJÓN, Ana Rosa, «El menor con discapacidad. Precariedad en la regulación y en políticas específicas», en, AA.VV., Los menores con discapacidad en España, Madrid, Ediciones CINCA, CERMI, 2008

MARTÍN J. Santiago, «La discapacidad como un problema social de derechos humanos», en, CAMPOY CERVERA, I., PALACIOS A., (Eds.), Igualdad, no discriminación y discapacidad. Una visión integradora de las realidades española y argentina, Madrid, Universidad Carlos III-Dykinson, 2007. 
MARTÍNEZ, J. L., (ed.), Exclusión Social y discapacidad, Madrid, España, Universidad Pontificia de Comillas, 2005.

MORENO, ANGARITA, M., «Pistas para el diálogo entre salud pública y discapacidad: hacia una comprensión de la evolución del concepto de discapacidad», Cuadernos del doctorado $n .{ }^{\circ} 8$, Salud pública y discapacidad, Universidad Nacional de Colombia, 2008, p. 76.

MUÑÓZ BORJA, P., Construcción de sentidos del mundo de la discapacidad y la persona con discapacidad. Estudios de casos, Cali, Colombia, Universidad del Valle, 2006.

OLIVER, M., ¿Una sociología de la discapacidad o una sociología discapacitada? En L. BARTON (Comp.). Discapacidad y sociedad, Madrid, Morata, 1998, pp. 34-58. Del mismo autor vid; The Politics of Disablement. Basingstoke: McMillan, 1990. Understanding Disability. Basingstoke: McMillan, 1996.

PALACIOS, A., El modelo social de discapacidad: orígenes, caracterización y plasmación en la Convención Internacional sobre los Derechos de las Personas con Discapacidad, Madrid, Ediciones CINCA, 2008.

PARRA DUSSAN, C., (Ed.), Derechos Humanos y discapacidad, Bogotá, Colombia, Centro Editorial Universidad del Rosario, 2004.

PÉREZ BUENO, L. C., Discapacidad, Derecho y Políticas Públicas, Madrid, Ed. Cinca, 2010.

PÉREZ PORTILLA, K., Principio de igualdad: alcances y perspectivas, México, UNAM-IIJ, 2005.

POLONIO, B., / RUIZ, J., «Accesibilidad integral», en, Rehabilitación clínica integral: funcionamiento y discapacidad, Barcelona España, Ed. Masson, 2003.

QUINN, G., / DEGENER T., (Eds.), Derechos Humanos y Discapacidad: Uso actual y posibilidades futuras de los instrumentos de Derechos Humanos de las Naciones Unidas en el contexto de la discapacidad, .Nueva York y Ginebra, Doc. HR/PUB/02/1, Naciones Unidas, 2002.

QUINN, P., Understanding Disability A Lifespan Approach, SAGE Publications, 1998.

— «Social Work and Disability Management Policy: Yesterday, today, and tomorrow», Social Work in Health Care, 1995.

RAWLS J., La justicia como equidad. Una reformulación, España, Ed. Paidós, 2001. 
